\title{
Gravimetric adsorption measurements of helium on natural clinoptilolite and synthetic molecular sieves at pressures up to $3500 \mathrm{kPa}$
}

\author{
Arash Arami-Niya, Thomas E. Rufford*, Greg Birkett, Zhonghua Zhu \\ School of Chemical Engineering, The University of Queensland, St Lucia 4072 Australia \\ *Corresponding author: t.rufford@uq.edu.au
}

\begin{abstract}
We report helium adsorption capacities and the true specific impenetrable solid volumes of a clinoptilolite-rich Escott zeolite from Werris Creek (Australia), synthetic 3A and 4A zeolites, and carbon molecular sieve 3K-172 measured by a gravimetric method at pressures of $(300-3500) \mathrm{kPa}$ and temperatures in the range of $(303-343) \mathrm{K}$. Our helium adsorption procedure extends the previous works by Gumma and Talu [1] to determine the impenetrable solid volume of the adsorbent, which in standard helium pycnometry is determined under the assumption that helium does not adsorb at room temperature. Our results confirm helium adsorption on these solids is small, but not zero: equilibrium helium adsorption capacities measured at $3500 \mathrm{kPa}$ and $303 \mathrm{~K}$ were $0.067 \mathrm{mmol} / \mathrm{g}$ on Escott, $0.085 \mathrm{mmol} / \mathrm{g}$ on $3 \mathrm{~A}$, $0.096 \mathrm{mmol} / \mathrm{g}$ on $4 \mathrm{~A}$ and $0.089 \mathrm{mmol} / \mathrm{g}$ on $3 \mathrm{~K}-172$. The specific solid volumes determined by the Gumma and Talu method were $10-15 \%$ larger than the specific solid volumes measured by standard helium pycnometry, and this error can result in uncertainties of $2.6-28 \%$ in the equilibrium adsorption capacities of $\mathrm{CO}_{2}$ and $\mathrm{N}_{2}$ measured at high pressures. The uncertainties were largest for $\mathrm{N}_{2}$ on the Escott zeolite, which had the lowest equilibrium adsorption capacity for $\mathrm{N}_{2}$. These results support the need to consider helium adsorption in the characterisation of adsorbents with narrow pore sizes, especially for adsorption processes that involve helium separations at low temperatures and/or high pressures.
\end{abstract}




\section{Nomenclature}

\begin{tabular}{|c|c|}
\hline$H$ & Henry’s constant, (mmol/g.kPa) \\
\hline$H_{0}$ & Entropy of adsorption, (mmol/g.kPa) \\
\hline$H_{1}$ & Isosteric heat of adsorption, $(\mathrm{kJ} / \mathrm{mol})$ \\
\hline$m_{a}$ & Adsorbed phase weight, (g) \\
\hline$m_{b}$ & True weight of sample basket and hook, (g) \\
\hline$m_{s}$ & True weight of solid adsorbent, (g) \\
\hline$m_{b a l}$ & mass recorded by balance at measuring point $1,(\mathrm{~g})$. \\
\hline$m_{t}{ }^{C a l c}$ & Calculated total weight, $(\mathrm{g})$ \\
\hline$m_{t}^{\text {Meas }}$ & Measured total weight, $(\mathrm{g})$ \\
\hline$m \mathrm{~W}_{\mathrm{ads}}$ & Molecular weight of adsorbate, $(\mathrm{g} / \mathrm{mol})$ \\
\hline$n_{a}$ & number of moles adsorbed, (mole) \\
\hline$P$ & Pressure, $(\mathrm{kPa})$ \\
\hline$Q_{a}$ & Amount of helium adsorbed per unit mass of the adsorbent, $(\mathrm{mmol} / \mathrm{g})$ \\
\hline$R$ & Molar gas constant, (kJ/K.mol) \\
\hline$V_{a}$ & Volume of adsorbed phase, $\left(\mathrm{cm}^{3}\right)$ \\
\hline$V_{b}$ & Volume of the sample basket and hook, $\left(\mathrm{cm}^{3}\right)$ \\
\hline$V_{s}$ & Impenetrable or inaccessible solid volume, $\left(\mathrm{cm}^{3}\right)$ \\
\hline$v_{s}$ & Specific inaccessible solid volume, $\left(\mathrm{cm}^{3} / \mathrm{g}\right)$ \\
\hline$V_{t}$ & Total volume, $\left(\mathrm{cm}^{3}\right)$ \\
\hline$\rho_{g}$ & Fluid density, $\left(\mathrm{g} / \mathrm{cm}^{3}\right)$ \\
\hline$\Delta m$ & Raw mass change, $(\mathrm{g})$ \\
\hline
\end{tabular}




\section{Introduction}

To measure adsorption of gases on porous solids with a high degree of accuracy requires the adsorbent's impenetrable solid volume $\left(V_{s}\right)$ to be determined precisely. The most common method used to determine $V_{s}$ is by volumetric helium pycnometry [2-4] because helium is small enough to access narrow pores (kinetic diameter of $2.60 \AA$ [5]) and helium has only weak interactions with solid surfaces. Typically, helium pycnometry is performed either in-situ within an adsorption measurement apparatus or in a separate pycnometer, and this procedure is based on the assumption that helium adsorption is negligible (i.e. mass helium adsorbed $\left.m_{a, H e}=0\right)[5,6]$. This assumption is reasonable for many adsorbents and conditions of relevance to most industrial processes. However, there is evidence in the literature $[2,7]$ that the uptake of helium on certain adsorbents may significantly affect the measurement of $V_{s}$ at low temperatures and high pressures. Thus, at high pressure conditions the standard helium expansion methods may lead to significant errors in the determination of $V_{s}[1,8]$, and these errors propagate as uncertainties in the estimation of the Gibbs dividing surface excess (GSE) $[8,9]$ and consequently as uncertainties in equilibrium capacities of other species such as $\mathrm{CO}_{2}$, $\mathrm{CH}_{4}$ and $\mathrm{N}_{2}$ measured at high pressures.

Although helium pycnometry is ubiquitous in the characterisation of porous materials, there are few reports of high pressure helium adsorption measurement techniques [1, 2, 7, 8, 10-14]. Most commercial adsorption instruments perform helium pycnometry at pressures close to $101.3 \mathrm{kPa}$ or in some high pressure instruments at pressures close to $500 \mathrm{kPa}$. Some theoretical and experimental approaches have been used to avoid using the limiting assumption that helium adsorption is zero. For example, Herrera et al. [3] proposed an alternative dividing surface to the traditional Gibbs dividing surface. From an experimental perspective, Sircar [8] and Gumma and Talu [1] have sought to develop methods that allow the true GSE to be approached 
more closely than the assumption of zero helium adsorption allows. Sircar's [8] approach was to determine the impenetrable solid volume $\left(V_{s}\right)$ and fix the Gibbs dividing surface by using helium as a probe molecule at temperatures where the Henry's Law constant $(H)$ approached zero. Gumma and Talu [1] modified Sircar's method by relaxing the assumption that helium uptake at any temperature was zero, and instead measured helium uptake at a range of temperatures up to $515 \mathrm{~K}$ to estimate a value for the Henry's Law constant.

In this study we tested Gumma and Talu's method with a gravimetric adsorption apparatus to measure the true void volumes and helium equilibrium adsorption capacities of a clinoptiloliterich natural zeolite (Escott), synthetic zeolites 3A and 4A, and a carbon molecular sieve. To examine the sensitivity of the equilibrium adsorption capacities measured at high pressure on these narrow pore adsorbents to the value of true void volume, we measured $\mathrm{CO}_{2}$ and $\mathrm{N}_{2}$ adsorption isotherms at pressures up to $4990 \mathrm{kPa}$ and temperatures in the range of $(298-323) \mathrm{K}$.

\section{Materials and materials characterisation}

Natural clinoptilolite-rich Escott zeolite from the Werris Creek deposit (New South Wales, Australia) was provided from Zeolite Australia Pty Limited, the synthetic zeolite molecular sieves 3A and 4A were provided by Sigma-Aldrich (Australia), and the carbon molecular sieve 3K-172 was provided by Shirasagi (Osaka Gas Chemicals Co. Ltd., Japan). The Escott zeolite was used as-received as an un-purified powder with particle sizes of less than $76 \mu \mathrm{m}$. The synthetic zeolites were in the form of beads with mesh sizes of $4-8$ for type $3 A$ and $8-12$ for type $4 \mathrm{~A}$. The $3 \mathrm{~K}-172$ carbon molecular sieve (CMS) was in the form of cylindrical, extruded pellets with diameter $1.8 \mathrm{~mm}$ and lengths in the range $1.18-2.8 \mathrm{~mm}(99 \%$ of particles in this size fraction according to technical specification sheet from Osaka Gas Chemicals Co. Ltd). 
The Escott clinoptilolite was selected as a low-cost, natural adsorbent available in commercial quantities that features narrow pores that are just accessible to helium. Clinoptilolite has a typical unit cell of $\mathrm{Na}_{6}\left[\left(\mathrm{Al}_{2} \mathrm{O}_{3}\right)_{8}\left(\mathrm{SiO}_{2}\right)_{28}\right] 24 \mathrm{H}_{2} \mathrm{O}$ and belongs to the heulandite (HEU) group $[15,16]$. This nanostructured material is composed of two parallel 10- and 8-membered ring channels of $0.72 \times 0.44 \mathrm{~nm}$ and $0.47 \times 0.41 \mathrm{~nm}$, respectively that are connected to a third channel with the windows size of $0.55 \times 0.40 \mathrm{~nm}$ [17]. Although the Werris Creek zeolite deposit is reported to be rich in clinoptilolite, thus natural material also contains other minerals such as mordenite, quartz, smectite clays and mica. We confirmed the presence of clinoptilolite in the Escott samples by powder X-ray diffraction (XRD, Bruker Advanced XRD) and MAS NMR spectra (AV-300 Brucker). The XRD pattern is shown in Figure $3 \mathrm{~S}$ of the Supporting Information (SI). The MAS NMR spectra collected at room temperature for the ${ }^{29} \mathrm{Si},{ }^{1} \mathrm{H}$ and ${ }^{27} \mathrm{Al}$ nuclei are included in Figure $4 \mathrm{~S} . \mathrm{NH}_{4} \mathrm{Al}\left(\mathrm{SO}_{4}\right)_{2} \cdot 12 \mathrm{H}_{2} \mathrm{O}$ was used as a reference for the chemical shifts. The ${ }^{27} \mathrm{Al}$ MAS NMR spectra was used to calculate a Si/Al ratio in the zeolite framework of $(\mathrm{Si} / \mathrm{Al})_{\mathrm{fw}}=6.587$ (Table $\left.2 \mathrm{~S}\right)$. Further information on the composition of the Escott zeolite sample is available in the technical data sheet provided by Zeolite Australia Pty Limited [18] and we have included the X-ray fluorescence date from the data sheet in Table 1S of the SI. Table 1S shows that the principal cations identified in the Escott zeolite were $\mathrm{K}^{+}, \mathrm{Ca}^{2+}, \mathrm{Fe}^{3+}$ and $\mathrm{Mg}^{2+}$, and as the cations affect the zeolite structure this data should be considered when comparing the Escott sorption capacities and selectivity to other natural or synthetic zeolites.

The synthetic zeolite molecular sieves $3 \mathrm{~A}$ and $4 \mathrm{~A}$ were selected for investigations because the structure of these materials is well characterised and the narrow pore openings of these zeolites allow only adsorption of small probe molecules such as like water, hydrogen and helium [19]. The structural framework of these zeolites is of the Linde Type A (LTA) cubically symmetric 
type. Zeolite $3 \mathrm{~A}$ is a synthetic crystalline potassium aluminosilicate that is usually obtained by ion exchange from the sodium form of zeolite type $4 \mathrm{~A}[20,21]$.

Pore textural properties of each adsorbent were characterized from sorption analyses of $\mathrm{CO}_{2}$ at 273 K measured with a TriStar II 3020 apparatus (Micromeritics, USA). The adsorbents were degassed at $473 \mathrm{~K}$ at a pressure of $10^{-2}$ Torr for 24 hours prior to sorption measurements on the TriStar II 3020. A summary of the pore volumes and surfaces areas measured is presented in Table 1, the $\mathrm{CO}_{2}$ isotherms measured on the TriStar II 3020 and the calculated pore size distributions are included in the SI. These results indicate that the $\mathrm{CO}_{2}$ equilibrium capacities at $273 \mathrm{~K}$ and $130 \mathrm{kPa}$ rank in the order $\mathrm{CMS}>4 \mathrm{~A}>$ clinoptilolite $>3 \mathrm{~A}$.

The purities of gases used in this work, as stated by the supplier Coregas Australia, were Grade $5(99.999 \%)$ for helium and nitrogen and grade $4.5(99.995 \%)$ for carbon dioxide.

\section{High pressure gravimetric adsorption apparatus}

Adsorption isotherms of pure helium on the four adsorbents were measured at (303 to 343) K and pressures up to $3500 \mathrm{kPa}$ using a BELSORP-BG high pressure gas adsorption instrument (BEL, Japan). A schematic of the BELSORP-BG instrument is shown in Figure 1. Prior to adsorption measurements the sample was degassed in-situ at $423 \mathrm{~K}$ under an ultimate vacuum of $1 \times 10^{-5}$ Torr, or lower, for 12 hours. The sample mass is measured continuously during an adsorption experiment using a magnetic floating balance (RUBOTHERM, Germany).

The sample basket is connected to the permanent magnet and the volume of the magnetic coupling section excluding the sample cell is constant throughout a measurement. The balance records three different positions during a single step of an adsorption measurement: (1) a zero point (ZP) is used to correct any drift in the balance between data points in an isotherm measurement; $(2)$ measuring point $1\left(m_{b a l}\right)$ records the location of the balance during the 
measurement and indicates the total weight change; and (3) measuring point 2 is used to determine the fluid density $\left(\rho_{g}\right)$ after the system reaches equilibrium by reference of the final balance position to the position when a titanium sinker (Figure 1) is lifted. The resolution and reproducibility of the gravimetric balance are $10^{-5} \mathrm{~g}$ and $\pm 3 \times 10^{-5} \mathrm{~g}$ (STD), and the density resolution and accuracy of the unit are $2 \times 10^{-6}$ and $\pm 2 \times 10^{-5} \mathrm{~g} / \mathrm{cm}^{3}$, respectively.

The absolute mass of adsorbed gas $\left(m_{a}\right)$ is determined from the weight recorded at measuring point $1\left(m_{b a l}\right)$ by a force balance on the system including the mass of the sample basket and balance hook $\left(m_{b}\right)$, the mass of the solid adsorbent $\left(m_{s}\right)$ and a correction for the buoyancy effect of the fluid (i.e. Archimedes principle). The force balance is shown in Equation 1:

$$
m_{b a l}=m_{b}+m_{s}+m_{a}-\left(V_{b}+V_{s}+V_{a}\right) \rho_{g}
$$

where the term $\left(V_{b}+V_{s}+V_{a}\right) \rho_{g}$ applies the buoyancy correction for the volume of the basket and hook $\left(V_{b}\right)$, the volume of the solid adsorbent that is not accessible to the adsorbate $\left(V_{s}\right)$ plus the volume of the adsorbed phase $\left(V_{a}\right)$. The volume of the adsorbed phase $\left(V_{a}\right)$ is negligible compared to $V_{b}+V_{s}$ and can be ignored from the buoyancy correction term. The empty basket volume $V_{b}$ is obtained from a calibration measurement made with helium across the range of temperatures and pressures of interest for the adsorption measurements. The masses of the degassed basket and sample are measured under an ultimate vacuum of $1 \times 10^{-5}$ Torr, a condition at which the buoyancy effect can be considered negligible since $\rho_{g}$ is essentially zero.

The remaining unknown variable in Equation 1 required to resolve the mass of adsorbed gas from the force balance is the volume of the solid adsorbent $V_{s}$. To determine the true solid volume $V_{s}$ and overcome the limitations of the conventional helium pycnometry measurements performed at close to ambient conditions, we followed the method of Gumma and Talu [1] as summarised in the Figure 2 flowchart. 


\section{Helium adsorption measurement procedure}

Steps 1, 2 and 3a in Figure 2 are described with the Belsorp-BG apparatus in Section 3. Step $3 \mathrm{~b}$ involves a rearrangement of the force balance in Equation 1 to obtain a reduced mass term $\Delta m$ from the buoyancy correction:

$$
\Delta m=m_{b}+m_{s}+m_{a}-m_{b a l}=\left(V_{b}+V_{s}\right) \rho_{g}
$$

Helium adsorption isotherms were measured at temperatures from $303 \mathrm{~K}$ to $343 \mathrm{~K}$ and Equation 2 was computed at each measurement temperature to plot $\Delta m$ against $\rho_{g}$ (which represents a unique equilibrium pressure condition in each isotherm). Figure 3 shows the $\Delta m$ plot for clinoptilolite from helium adsorption measurements at temperatures of (303 - 343) K and pressures up to $3500 \mathrm{kPa}$. The gradient of the plot in Figure 3 represents the volume $V_{b}+V_{s}$ and is first calculated as a straight line passing through the origin. As the value of $V_{b}$ is already known for each temperature from the Belsorp-BG calibrations and the thermal expansion of the adsorbent is negligible over the measured temperature range [22], then the slope $V_{b}+V_{s}$ should be constant at all temperatures if there were no helium uptake on the solid. However, Figure 4 shows that for helium on clinoptilolite the apparent volume $V_{b}+V_{s}$ determined from the slope of $\Delta m$ against $\rho_{g}$ increases more than could be attributed to thermal expansion of the solid (volumetric thermal expansion coefficient approximately $1.7 \times 10^{-9} \mathrm{~cm}^{3} /\left(\mathrm{cm}^{3} . \mathrm{K}\right)$ ). This result suggests a measurable mass of helium has been adsorbed and the observation is consistent with other high pressure helium adsorption studies [1, 12, 14, 23].

Step 5 of the helium measurement procedure in Figure 2 tests the assumption that helium adsorption at the measurement conditions follows Henry's Law [13, 24]: 


$$
m_{a}=M W_{a d s} n_{a}=M W_{a d s} H P
$$

where $M W_{a d s}$ is the molecular weight of the adsorbate, $n_{a}$ is the number of moles adsorbed and $H$ is the Henry's Law constant. Equation 3 can be substituted in the Equation 1 force balance with replacement of the adsorbent volume $V_{s}$ with $m_{s} v_{s}$, where $v_{s}$ represents the specific inaccessible volume of the solid $\left(V_{s} / m_{s}\right)$ to obtain:

$$
m_{b a l}=m_{b}+m_{s}+\left[m_{s} H R T-\left(V_{b}+m_{s} v_{s}\right)\right] \rho_{g}
$$

Here the pressure $P$ is evaluated using the ideal gas law and the fluid density measured at each isotherm point by the gravimetric balance. The uncertainty introduced in the calculation of mass of helium adsorbed by the use of the ideal gas law in Equation 4 is less than $1 \%$ at the measured pressure range because the measurement temperatures are well above helium's critical temperature of $5.2 \mathrm{~K}$.

The temperature dependence of the Henry's constant can be represented by an Arrhenius type equation with entropy related $H_{0}$ and isosteric heat $H_{1}$ of adsorption parameters [25] to yield Equation 5 and a model force balance Equation 6 that represents the adsorption isotherm:

$$
\begin{aligned}
& H=H_{0} \exp \left(\frac{H_{1}}{R T}\right) \\
& m_{b a l}=m_{b}+m_{s}+\left[m_{s} H_{0} \exp \left(\frac{H_{1}}{R T}\right) R T-\left(V_{b}+m_{s} v_{s}\right)\right] \rho_{g}
\end{aligned}
$$

A least-squares regression analysis was used to determine the best-fit parameters $v_{s}, H_{0}$, and $H_{1}$ in Equation 6 by minimizing the standard deviation $\left(S D=\left((1 / N) \Sigma\left(m_{t}^{\text {Calc }}-m_{t}^{\text {Meas }}\right)^{2}\right)^{1 / 2}\right.$ where $N$ is the number of data points regressed) between the measured mass $m_{b a l}^{\text {Meas }}$ and the mass calculated with Equation $6 m_{b a l}^{\text {Calc }}$ for the five different temperatures. The best fit 
parameters for helium on clinoptilolite, and the other three adsorbents studied, are summarised in Table 2.

We found one challenge in obtaining the best-fit parameters for Equation 6 with the measured data sets was finding an optimised solution with a value for the heat of adsorption parameter $H_{1}$ that was consistent with expected values from other theoretical and experimental studies. To address this challenge, we performed a series of regressions to find $H_{0}$ and $v_{s}$ for values of $H_{l}$ in the range of $(0-8) \mathrm{kJ} / \mathrm{mol}$ and the sensitivity of the final result to choice of $H_{l}$ is shown in Figure 5S. Although the selection of $\mathrm{H}_{1}$ values within the range of $(0-8) \mathrm{kJ} / \mathrm{mol}$ does not have a significant effect on the overall fit of the model to the measured data (SDs were less than $2 \times 10^{-5} \mathrm{~g}$ for all cases), the values for $v_{s}$ of obtained for the synthetic zeolites $3 \mathrm{~A}$ and $4 \mathrm{~A}$ when $H_{l}$ was set to values less than $3 \mathrm{~kJ} / \mathrm{mol}$ were significantly larger than the possible range of solid volumes that have been calculated from the cage structures of these zeolites and the other experimental measurements $[13,26]$. For the Escott zeolite the $v_{s}$ determined at $H_{1}<3 \mathrm{~kJ} / \mathrm{mol}$ was smaller than the solid volume determined by helium pycnometry and this result is not consistent with the hypothesis that helium adsorption is none zero (adsorption cannot be negative). Furthermore, at $H_{1}<3 \mathrm{~kJ} / \mathrm{mol}$ a wide variation in the values of $H_{0}$ is produced and that result is not convincing because the strength of interaction between helium molecules and the adsorbents should be relatively independent of the type of solid [27, 28]. The regression results obtained for values of $H_{l}$ of $3 \mathrm{~kJ} / \mathrm{mol}$ to $8 \mathrm{~kJ} / \mathrm{mol}$ include feasible solid volumes $v_{s}$, and similar values of $H_{0}$ for all fours solids. This range of heat of adsorption values is then also consistent then also consistent published heats of adsorption for helium on silicalite $(3.9 \mathrm{~kJ} / \mathrm{mol})$ [1], 5 A zeolite $(5.8 \mathrm{~kJ} / \mathrm{mol}), 13 \mathrm{X}$ zeolite $(4.8 \mathrm{~kJ} / \mathrm{mol})$, alumina $(2.9 \mathrm{~kJ} / \mathrm{mol})$, and BPL activated carbon $(3.1 \mathrm{~kJ} / \mathrm{mol})$ [8]. The narrow range of reported heats of adsorption for helium is related to the absence of permanent dipole or quadrupole moment of $\mathrm{He}$ and weak adsorbate-solid interactions which makes heat of adsorption relatively independent of sorbent 
type $[27,28]$. Therefore, although the regression analysis for these data sets leaves some uncertainty in the values of $H_{l}$ the analysis and other reported heats of adsorption of helium on microporous adsorbents [1, 8, 13, 27-29] lead us to select $H_{1}=3 \mathrm{~kJ} / \mathrm{mol}$. The sensitivity of the measured helium adsorption capacities to this decision is illustrated by the error bars shown in Figure 6 to Figure 8.

With $H_{l}=3 \mathrm{~kJ} / \mathrm{mol}$ the force balance model in Equation 6 predictions of $m_{b a l}^{\text {Calc }}$ for the measured weight $m_{b a l}^{\text {Meas }}$ of helium adsorbed on Escott zeolite have a standard deviation of $3.85 \times 10^{-5} \mathrm{~g}$ and an average relative errors in the order of $10^{-4} \%$ from the measured weight $m_{b a l}^{\text {Meas }}$, which indicates the model provides a good fit of the experimental data. The Henry's Law constant for the helium adsorption on clinoptilolite at $303 \mathrm{~K}$ was $1.7 \times 10^{-2} \mathrm{mmol} / \mathrm{kg} . \mathrm{kPa}$, which is the same order of magnitude as the Henry's Law constant of $2.4 \times 10^{-3} \mathrm{mmol} / \mathrm{kg} . \mathrm{kPa}$ that can be calculated for helium adsorption on silicate at temperature of $303 \mathrm{~K}$ from the data provided by Gumma and Talu [1]. Clearly, these Henry's Law constants for helium are much smaller than equilibrium parameters for more strongly adsorbed gases such as $\mathrm{CO}_{2}$ [25]. Nonetheless, these results demonstrate measurable helium adsorption on clinoptilolite and the data supports the argument that the Henry's Law constant is a critical parameter required to estimate void volumes from helium pycnometer measurements; this requirement is most critical for measurements of the surface excess isotherms performed at high pressures and low temperatures [8].

Table 2 shows that the specific impenetrable solid volume of Escott zeolite determined by (i) the Gumma and Talu method was $v_{s, G T}=0.461 \mathrm{~cm}^{3} / \mathrm{g}$ and (ii) the standard helium pycnometry [8] was $v_{P y c}=0.422 \mathrm{~cm}^{3} / \mathrm{g}$, which is $8.46 \%$ smaller than $v_{s, G T}$. The impenetrable solid volume from Gumma and Talu's method will be used throughout this manuscript. Once $v_{s, G T}$ has been 
determined we return to the force balance in Equation 1 to compute the helium adsorption isotherms for Escott zeolite presented in Figure 5 and Table 3. The helium adsorption capacities on Escott zeolite shown in Figure 5 are of similar magnitudes to helium uptakes on other narrow-pore inorganic materials reported in the literature. For example, we measured $0.067 \mathrm{mmol} / \mathrm{g}$ helium uptake on Escott zeolite at $303 \mathrm{~K}$ and $3500 \mathrm{kPa}$ and Gumma and Talu [1] reported $0.078 \mathrm{mmol} / \mathrm{g}$ helium on silicalite at $302 \mathrm{~K}$ and $3300 \mathrm{kPa}$.

In Figure 5, the error bars marked on the $303 \mathrm{~K}$ isotherm represent the uncertainty in the helium adsorption capacity estimated from (1) the measurement uncertainty in the magnetic suspension balance and (2) the uncertainties that result from the data analysis procedures used to determine $v_{s, G T}$, which includes the uncertainty due to the heat of adsorption described above. The resolution of the temperature sensors $(\operatorname{Pt} 100 \Omega)$ was $\pm 0.15 \mathrm{~K}$, and thus the uncertainty introduced to the fitted parameters by the temperature measurements is considered to be negligible. Note that in the this method data from the Belsorp-BG pressure transducers is not used directly in the calculations of adsorption capacities or $v_{s, G T}$ (the measured fluid density is used); instead the measured pressure data is used only to locate each equilibrium data point on the pressure axes in Figures $5-8$.

In addition to the Escott zeolite measurements, we determined $v_{s, G T}$ and excess adsorption capacities for helium on zeolite 3A, zeolite 4A and CMS 3K-172. The specific solid volumes and best-fit best-fit parameters for Equation 6 for these adsorbents are shown in Table 2. The excess helium adsorption capacities measured at $(303-343) \mathrm{K}$ and pressures up to $3500 \mathrm{kPa}$ are presented Figure 6, Figure 7 and Figure 8. Tabulated adsorption capacities for these adsorbents are included in the SI. The helium adsorption capacities measured at $3500 \mathrm{kPa}$ and $303 \mathrm{~K}$ were $0.085 \mathrm{mmol} / \mathrm{g}$ for $3 \mathrm{~A}, 0.096 \mathrm{mmol} / \mathrm{g}$ on $4 \mathrm{~A}$ and $0.089 \mathrm{mmol} / \mathrm{g}$ on CMS. For these adsorbents the standard deviations of the model calculated total weights from the measured 
data $\left(m_{b a l}^{\text {Calc }}-m_{b a l}^{\text {Meas }}\right)$ show that the model provides a good fit to the measured data. There is some scatter in the isotherm data points measured at different temperatures, for example in Figure 8 some equilibrium data points for CMS 3K-172 show higher adsorption capacities at $333 \mathrm{~K}$ than at $323 \mathrm{~K}$. However, as the heats of adsorption and adsorption capacities for helium are small these results are well within the estimated uncertainty of the measurement and data analysis procedures that are indicated by error bars on each excess adsorption isotherm figure. The uncertainty in the helium adsorption measurement reported here could be improved by performing the measurements at a wider temperature range than we could perform on our laboratory apparatus (Belsorp-BG), for example experiments could be performed on other gravimetric instruments at cryogenic temperatures through to approximately $515 \mathrm{~K}$.

\section{High pressure adsorption equilibria of nitrogen and carbon dioxide}

Measurements of $\mathrm{CO}_{2}$ and $\mathrm{N}_{2}$ on the Escott zeolite, zeolite $4 \mathrm{~A}$ and $\mathrm{CMS}$ were made at pressures in the range $(10-4500) \mathrm{kPa}$ and at temperatures close to room temperature, and then excess adsorption capacities were calculated using (i) the $v_{\mathrm{s}, \mathrm{GT}}$ determined by the Gumma and Talu method and (ii) the $v_{s, P y c}$ determined by standard helium pycnometry. Figure 9 shows the excess adsorption isotherms determined for $\mathrm{CO}_{2}$ and $\mathrm{N}_{2}$ using each of these methods. The adsorption capacities for $\mathrm{CO}_{2}$ and $\mathrm{N}_{2}$ on $4 \mathrm{~A}$ and $\mathrm{CMS}$ that we measured are consistent with results reported in other studies with these materials [30-33]. The tabulated equilibrium data and differences between results obtained with the two methods, $\Delta Q=Q_{G T}-Q_{P y c}$ where $Q_{G T}$ is calculated with $v_{s, G T}$ and $Q_{P, c}$ with $v_{s, P y c}$, are provided in Table $6 \mathrm{~S}$ of the SI. The deviation $\Delta Q=Q_{G T}-Q_{P, c}$ is greatest when (a) the error between the true void volume and standard helium pycnometry void volume is large (Table 2) and (b) the adsorption capacity of $\mathrm{CO}_{2}$ or $\mathrm{N}_{2}$ is small. For example, the relative error associated with the $v_{s, P y c}$ determined under the assumption of zero helium 
adsorption in the measured $\mathrm{CO}_{2}$ capacity of $0.966 \mathrm{mmol} / \mathrm{g}$ on Escott zeolite at $3500 \mathrm{kPa}$ is approximately $5.1 \%$ but for the less-strongly adsorbed $\mathrm{N}_{2}$ on Escott zeolite $\left(0.276 \mathrm{mmol} / \mathrm{g} \mathrm{N}_{2}\right)$ this error grows to be as large as $28 \%$ at pressures up to $5000 \mathrm{kPa}$. However, as zeolite 4A adsorbed a lot more $\mathrm{N}_{2}$ and $\mathrm{CO}_{2}$ than the Escott zeolite the $11 \%$ difference in impenetrable void volumes of $4 \mathrm{~A}$ determined by the two methods results in an underestimation of only $0.085 \mathrm{mmol} / \mathrm{g}(6 \%)$ for $\mathrm{N}_{2}$ at $3393 \mathrm{kPa}$ and $0.115 \mathrm{mmol} / \mathrm{g} \mathrm{CO}_{2}$ at $3990 \mathrm{kPa}$ (3\% error). The adsorption capacities of helium, $\mathrm{CO}_{2}$ and $\mathrm{N}_{2}$ on $\mathrm{CMS} 3 \mathrm{~K}-172$ are similar to the capacities on 4A, and for CMS the differences in adsorption capacities due to the method for determining $v_{s}$ is only $2.6 \%$ for $\mathrm{CO}_{2}$ at $3492 \mathrm{kPa}$ and $2.9 \%$ for $\mathrm{N}_{2}$ at $4500 \mathrm{kPa}$.

These results show that measurement errors in the true adsorbent volume determined in typical commercial adsorption instruments by helium pycnometry at pressures up to $500 \mathrm{kPa}$ introduce only minor errors in adsorption capacities measured at high pressures if the adsorbent has a high adsorption capacity. However, as the Escott results highlight, if the adsorbent has narrow pores than the adsorption of helium during pycnometry may lead to material errors in the measurement of adsorption capacities of other gases $\left(\mathrm{CO}_{2}, \mathrm{~N}_{2}\right)$ at high pressures. This error may be more noticeable in volume calibration of adsorbents using helium at high pressures or low temperatures and affects the accuracy of the adsorption measurements.

\section{Conclusion}

We applied the method of Gumma and Talu [1] to determine impenetrable volumes of a clinoptilolite-rich natural Escott zeolite, zeolite 3A, zeolite 4A and CMS 3K-172, and helium adsorption isotherms using a gravimetric adsorption apparatus. This method is not constrained by the assumption that helium adsorption is zero during the procedures to determine the impenetrable solid volume, and thus this method may be useful for characterisation of narrowpore adsorbents that may adsorb significant volumes of helium at low temperatures and high 
pressures. The equilibrium helium adsorption capacities measured at $3500 \mathrm{kPa}$ and $303 \mathrm{~K}$ were $0.067 \mathrm{mmol} / \mathrm{g}$ on Escott, $0.085 \mathrm{mmol} / \mathrm{g}$ on zeolite $3 \mathrm{~A}, 0.096 \mathrm{mmol} / \mathrm{g}$ on zeolite $4 \mathrm{~A}$ and $0.089 \mathrm{mmol} / \mathrm{g}$ on CMS 3K-172. The heat of adsorption of helium on each adsorbent was estimated to be $3 \mathrm{~kJ} / \mathrm{mol}$, and although this result is consistent with other studies, the precise determination of this parameter was limited by the range of temperatures we could measure on our apparatus and better results may be possible with measurements at a wider range of temperatures.

The true specific solid volumes determined by this method were $10-15 \%$ larger than the specific solid volumes measured by standard helium pycnometry and this error can result in uncertainties of $2.6-28 \%$ in the adsorption capacities of $\mathrm{CO}_{2}$ and $\mathrm{N}_{2}$ on these sorbents at high pressures. The errors were largest for $\mathrm{N}_{2}$ on the Escott zeolite which had the lowest equilibrium adsorption capacity for $\mathrm{N}_{2}$. These results support the need to consider helium adsorption in characterisation of adsorbents with narrow pore sizes; this consideration may be most critical if the adsorbent is being evaluated for use in a helium purification process or for use in an adsorption process that operates at low temperatures or high pressures. However, the effect of helium adsorption during determination of solid volumes on the $\mathrm{CO}_{2}$ and $\mathrm{N}_{2}$ equilibrium capacities measured for $4 \mathrm{~A}$ and CMS $3 \mathrm{~K}-172$ in this study also suggest that for many adsorption applications the standard helium pycnometry methods are satisfactory.

\section{Acknowledgements}

This research was funded by the Australian Research Council (DE140100569) with additional scholarship support for Mr Arami-Niya provided through a UQ International Postgraduate Research Scholarship. We thank Dr Ge Lei for technical assistance in the laboratory. We acknowledge the facilities and technical assistance of the Australian Microscopy \& 
Microanalysis Research facility at the Centre for Microscopy \& Microanalysis at the University of Queensland. 


\section{References}

[1] S. Gumma, O. Talu, Gibbs Dividing Surface and Helium Adsorption, Adsorption, 9 (2003) 17-28.

[2] K. Lorenz, M. Wessling, How to determine the correct sample volume by gravimetric sorption measurements, Adsorption, 19 (2013) 1117-1125.

[3] L. Herrera, C. Fan, D.D. Do , D. Nicholson, A revisit to the Gibbs dividing surfaces and helium adsorption, Adsorption, 17 (2011) 955-965.

[4] A.L. Myers, Thermodynamics of adsorption in porous materials, AIChE Journal, 48 (2002) 145-160.

[5] A. Myers, P. Monson, Physical adsorption of gases: the case for absolute adsorption as the basis for thermodynamic analysis, Adsorption, 20 (2014) 591-622.

[6] H.H. Funke, Y. Luo, M.Z. Chen, G.C. Anderson, J.L. Falconer, R.D. Noble, Measuring Mixture Adsorption by Temperature-Programmed Desorption, Industrial \& Engineering Chemistry Research, 54 (2015) 5159-5164.

[7] F.A.P. Maggs, P.H. Schwabe, J.H. Williams, Adsorption of Helium on Carbons: Influence on Measurement of Density, Nature, 186 (1960) 956-958.

[8] S. Sircar, Measurement of gibbsian surface excess, AIChE Journal, 47 (2001) 1169-1176.

[9] R. Pini, Interpretation of net and excess adsorption isotherms in microporous adsorbents, Microporous and Mesoporous Materials, 187 (2014) 40-52.

[10] R.B. Hallock, Y.H. Kahng, Adsorption of helium and other gases to carbon nanotubes and nanotube bundles, Journal of Low Temperature Physics, 134 (2004) 21-30.

[11] T. Herman, J. Day, J. Beamish, Helium adsorption in silica aerogel near the liquid-vapor critical point, Physical Review B - Condensed Matter and Materials Physics, 72 (2005).

[12] D.S. Tomar, M. Singla, S. Gumma, Potential parameters for helium adsorption in silicalite, Microporous and Mesoporous Materials, 142 (2011) 116-121.

[13] P. Malbrunot, D. Vidal, J. Vermesse, R. Chahine, T.K. Bose, Adsorbent Helium Density Measurement and Its Effect on Adsorption Isotherms at High Pressure, Langmuir, 13 (1997) 539-544.

[14] I. Suzuki, K. Kakimoto, S. Oki, Volumetric determination of adsorption of helium over some zeolites with a temperature-compensated, differential tensimeter having symmetrical design, Review of Scientific Instruments, 58 (1987) 1226-1230.

[15] D.W. Breck, Zeolite molecular sieves: structure, chemistry, and use, R.E. Krieger1984.

[16] D.W. Ming, J.B. Dixon, Technique for the separation of clinoptilolite from soils, Clays and Clay Minerals, 35 (1987) 469-472.

[17] A. Jayaraman, R.T. Yang, D. Chinn, C.L. Munson, Tailored Clinoptilolites for Nitrogen/Methane Separation, Industrial \& Engineering Chemistry Research, 44 (2005) 51845192.

[18] Chemical and Physical Analysis of Escott Zeolite, Zeolite Australia Pty Ltd2012. 
[19] E. Gabruś, J. Nastaj, P. Tabero, T. Aleksandrzak, Experimental studies on 3A and 4A zeolite molecular sieves regeneration in TSA process: Aliphatic alcohols dewatering-water desorption, Chemical Engineering Journal, 259 (2015) 232-242.

[20] L.B. McCusker, D.H. Olson, C. Baerlocher, Atlas of Zeolite Framework Types, 2007.

[21] M. Llano-Restrepo, M.A. Mosquera, Accurate correlation, thermochemistry, and structural interpretation of equilibrium adsorption isotherms of water vapor in zeolite $3 \mathrm{~A}$ by means of a generalized statistical thermodynamic adsorption model, Fluid Phase Equilibria, 283 (2009) 73-88.

[22] P. Tschaufeser, S.C. Parker, Thermal Expansion Behavior of Zeolites and AlPO4s, The Journal of Physical Chemistry, 99 (1995) 10609-10615.

[23] Z. Bolboli Nojini, A. Abbas Rafati, S. Majid Hashemianzadeh, S. Samiee, Predicting helium and neon adsorption and separation on carbon nanotubes by Monte Carlo simulation, Journal of Molecular Modeling, 17 (2011) 785-794.

[24] D.M. Ruthven, Principles of Adsorption and Adsorption Processes, Wiley, New York, 1984.

[25] F.N. Ridha, P.A. Webley, Anomalous Henry's law behavior of nitrogen and carbon dioxide adsorption on alkali-exchanged chabazite zeolites, Separation and Purification Technology, 67 (2009) 336-343.

[26] K. Loughlin, Water isotherm models for 4A (NaA) zeolite, Adsorption, 15 (2009) 337353.

[27] J.E. Koresh, A. Danon, A Novel Insight on the High-Temperature Helium Interaction with a Carbon Molecular Sieve, Langmuir, 17 (2001) 2739-2742.

[28] A.J. Lachawiec, T.R. DiRaimondo, R.T. Yang, A robust volumetric apparatus and method for measuring high pressure hydrogen storage properties of nanostructured materials, Review of Scientific Instruments, 79 (2008) 063906.

[29] T. Wilson, O.E. Vilches, Helium adsorbed on carbon nanotube bundles: one-dimensional and/or two-dimensional solids?, Low Temperature Physics, 29 (2003) 732-735.

[30] A. Jayaraman, A.J. Hernandez-Maldonado, R.T. Yang, D. Chinn, C.L. Munson, D.H. Mohr, Clinoptilolites for nitrogen/methane separation, Chemical Engineering Science, 59 (2004) 2407-2417.

[31] H. Faghihian, M. Talebi, M. Pirouzi, Adsorption of nitrogen from natural gas by clinoptilolite, JICS, 5 (2008) 394-399.

[32] M.W. Ackley, R.T. Yang, Adsorption characteristics of high-exchange clinoptilolites, Industrial \& Engineering Chemistry Research, 30 (1991) 2523-2530.

[33] R.W. Triebe, F.H. Tezel, Adsorption of nitrogen, carbon monoxide, carbon dioxide and nitric oxide on molecular sieves, Gas Separation \& Purification, 9 (1995) 223-230. 


\section{Tables}

Table 1 Micropore surface area $\left(\mathrm{m}^{2} / \mathrm{g}\right)$ and micropore volume $\left(\mathrm{cm}^{3} / \mathrm{g}\right)$ of Escott zeolite, zeolites $3 \mathrm{~A}$ and $4 \mathrm{~A}$, and carbon molecular sieve CMS $3 \mathrm{~K}-172$ calculated from $\mathrm{CO}_{2}$ adsorption isotherms measured at $273 \mathrm{~K}$. Micropore surface areas were calculated using the Dubinin-Radushkevich (D-R) equation and micropore volumes were estimated applying the Dubinin-Astakhov (D-A) equation.

$$
\begin{gathered}
\text { Micropore surface area, D-R } \\
\left(\mathrm{m}^{2} / \mathrm{g}\right)
\end{gathered} \quad \begin{gathered}
\text { Limiting micropore volume, D-A } \\
\left(\mathrm{cm}^{3} / \mathrm{g}\right)
\end{gathered}
$$

Escott zeolite

Zeolite 3A

Zeolite 4A

CMS 3K-172
100

0.041

0.008

332

0.098

482

0.17 
Table 2 Best-fit parameters for the helium adsorption isotherm model in Equation 6 for helium adsorption on clinoptilolite-rich Escott zeolite, zeolites 3A and 4A and carbon molecule sieve 3K-172. The specific impenetrable solid volumes shown are $v_{s, G T}$ determined using Gumma and Talu's method and $v_{s, P y c}$ obtained from standard helium pycnometry performed at close to ambient pressure conditions.

\section{Best-fit parameters for helium adsorption procedure}

Standard helium pycnometery

\begin{tabular}{|c|c|c|c|c|c|}
\hline Material & $\begin{array}{c}v_{S, G T} \\
\left(\mathrm{~cm}^{3} / \mathrm{g}\right)\end{array}$ & $\begin{array}{c}\mathrm{H}_{0} \\
(\mathrm{mmol} /(\mathrm{kg} . \mathrm{kPa}))\end{array}$ & $\begin{array}{c}\mathrm{H}_{1} \\
(\mathrm{~kJ} / \mathrm{mol})\end{array}$ & $S D(g)$ & $\begin{array}{c}v_{s, P y c} \\
\left(\mathrm{~cm}^{3} / g\right)\end{array}$ \\
\hline Escott zeolite & 0.461 & $5.14 \times 10^{-3}$ & 3 & $3.9 \times 10^{-5}$ & 0.422 \\
\hline Zeolite 3A & 0.487 & $5.72 \times 10^{-3}$ & 3 & $3.9 \times 10^{-5}$ & 0.410 \\
\hline Zeolite 4A & 0.492 & $5.62 \times 10^{-3}$ & 3 & $1.9 \times 10^{-5}$ & 0.438 \\
\hline CMS 3K-172 & 0.546 & $7.57 \times 10^{-3}$ & 3 & $8.1 \times 10^{-5}$ & 0.487 \\
\hline
\end{tabular}

$S D=\left((1 / N) \sum\left(m_{t}^{\text {Calc }}-m_{t}^{\text {Meas }}\right)^{2}\right)^{1 / 2}$ 
Table 3 Helium adsorption equilibrium data on the clinoptilolite-rich Escott zeolite.

\begin{tabular}{|c|c|c|c|c|c|}
\hline \multicolumn{3}{|c|}{$\mathrm{T}=303 \mathrm{~K}$} & \multicolumn{3}{|c|}{$\mathrm{T}=333 \mathrm{~K}$} \\
\hline$P(k P a)$ & $\Delta m(m g)$ & $Q_{a}(\mathrm{mmol} / \mathrm{g})$ & $P(k P a)$ & $\Delta m(g)$ & $Q_{a}(\mathrm{mmol} / \mathrm{g})$ \\
\hline 309.4 & -0.79 & 0.006 & 307.8 & -0.71 & 0.007 \\
\hline 707.1 & -1.83 & 0.009 & 709.6 & -1.67 & 0.008 \\
\hline 1008.6 & -2.61 & 0.013 & 1011.3 & -2.38 & 0.012 \\
\hline 1507.7 & -3.90 & 0.021 & 1508.7 & -3.55 & 0.018 \\
\hline 2005.4 & -5.18 & 0.030 & 2006.7 & -4.71 & 0.027 \\
\hline 3006.4 & -7.72 & 0.056 & 3004.5 & -7.04 & 0.043 \\
\hline 3501.8 & -8.99 & 0.067 & 3502.2 & -8.19 & 0.054 \\
\hline \multicolumn{3}{|c|}{$\mathrm{T}=313 \mathrm{~K}$} & \multicolumn{3}{|c|}{$\mathrm{T}=343 \mathrm{~K}$} \\
\hline$P(k P a)$ & $\Delta m(m g)$ & $Q_{a}(\mathrm{mmol} / \mathrm{g})$ & $P(k P a)$ & $\Delta m(g)$ & $Q_{a}(\mathrm{mmol} / \mathrm{g})$ \\
\hline 309.6 & -0.77 & 0.007 & 310.6 & -0.71 & 0.005 \\
\hline 709.7 & -1.76 & 0.014 & 709.7 & -1.63 & 0.010 \\
\hline 1009.6 & -2.54 & 0.012 & 1008.9 & -2.31 & 0.010 \\
\hline 1507.1 & -3.76 & 0.026 & 1508.5 & -3.44 & 0.018 \\
\hline 2008.2 & -5.02 & 0.031 & 2007.3 & -4.58 & 0.029 \\
\hline 3002.6 & -7.47 & 0.054 & 3003.3 & -6.83 & 0.037 \\
\hline 3503.3 & -8.71 & 0.064 & 3504.5 & -7.96 & 0.049 \\
\hline
\end{tabular}

$\mathrm{T}=323 \mathrm{~K}$

\begin{tabular}{ccc}
\hline$P(\mathrm{kPa})$ & $\Delta m(\mathrm{~g})$ & $Q_{a}(\mathrm{mmol} / \mathrm{g})$ \\
\hline 307.1 & -0.74 & 0.005 \\
708.4 & -1.72 & 0.008 \\
1009.0 & -2.45 & 0.012 \\
1507.6 & -3.65 & 0.021 \\
2007.2 & -4.87 & 0.026 \\
3003.6 & -7.26 & 0.045 \\
3504.7 & -8.45 & 0.059
\end{tabular}




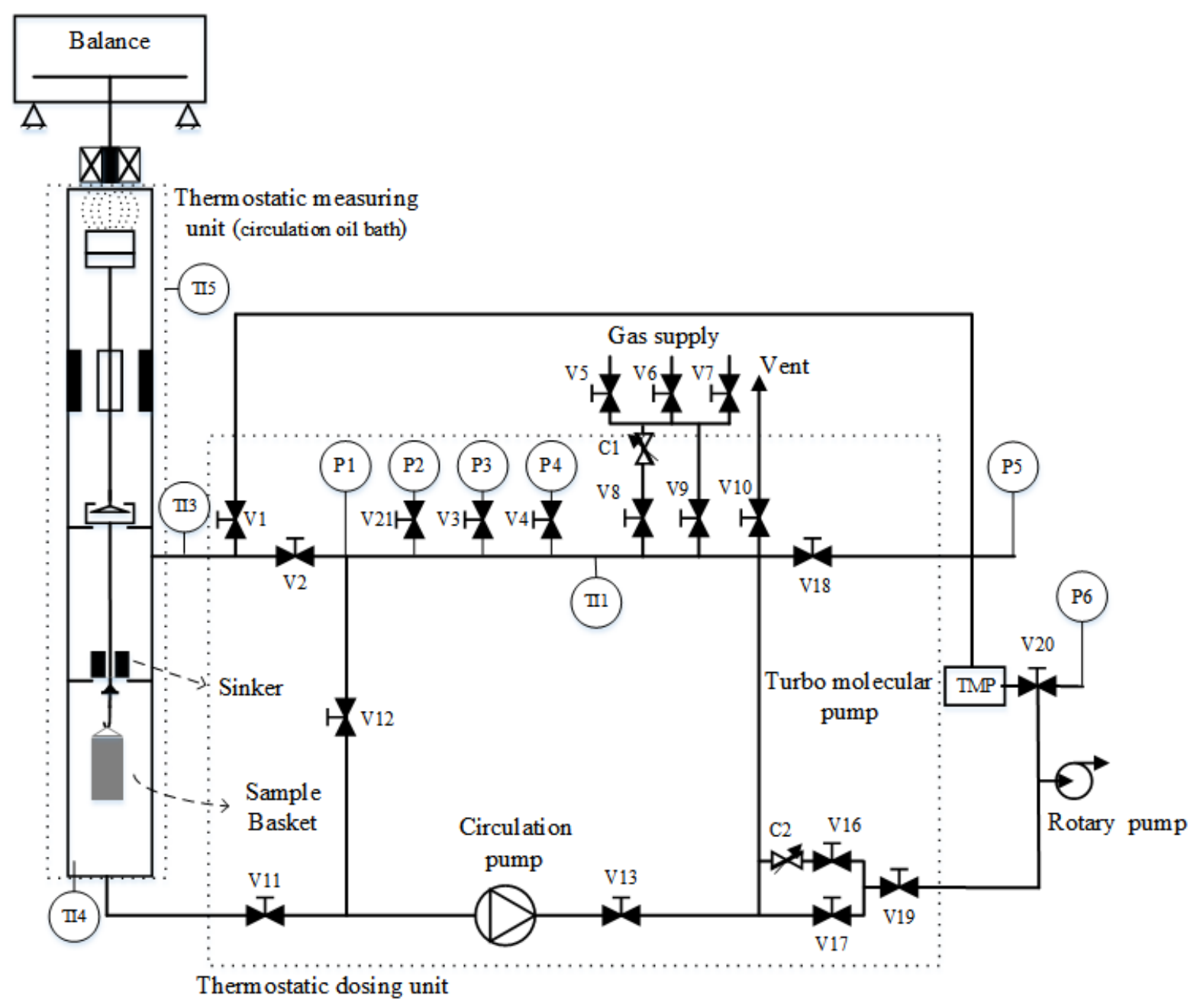

Figure 1 Schematic of BELSORP-BG gravimetric adsorption apparatus. Key to symbols: P1-6: pressure sensor, C1-2: Automatic control valve. TI1-4: Temperature indicator (controller), V1-21: Normal closed type pneumatic-actuated valve 
Calibration measurements $V_{b u}, m_{b u}$
1. Measure $m_{s}$ under vacuum conditions

$m_{s}$

2. Perform adsorption

measurement with $\mathrm{He}$ at $(P, T)_{\text {, }}$

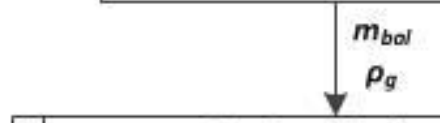

3a. Force Balance

$m_{b a^{\prime}}=m_{b}+m_{s}+m_{a}-\left(V_{b}+V_{s}\right) \rho_{2}$

3b. Plot

$\left(m_{b}+m_{s}+m_{a}-m_{b a}\right)$ vs $\rho_{a}$

Slope $=V_{b}+V_{s}=V_{t}$

4.

Does $V_{t}$ vary for with T?

No uptake, $m_{a}=0$ $V_{s}=V_{t}-V_{b}$

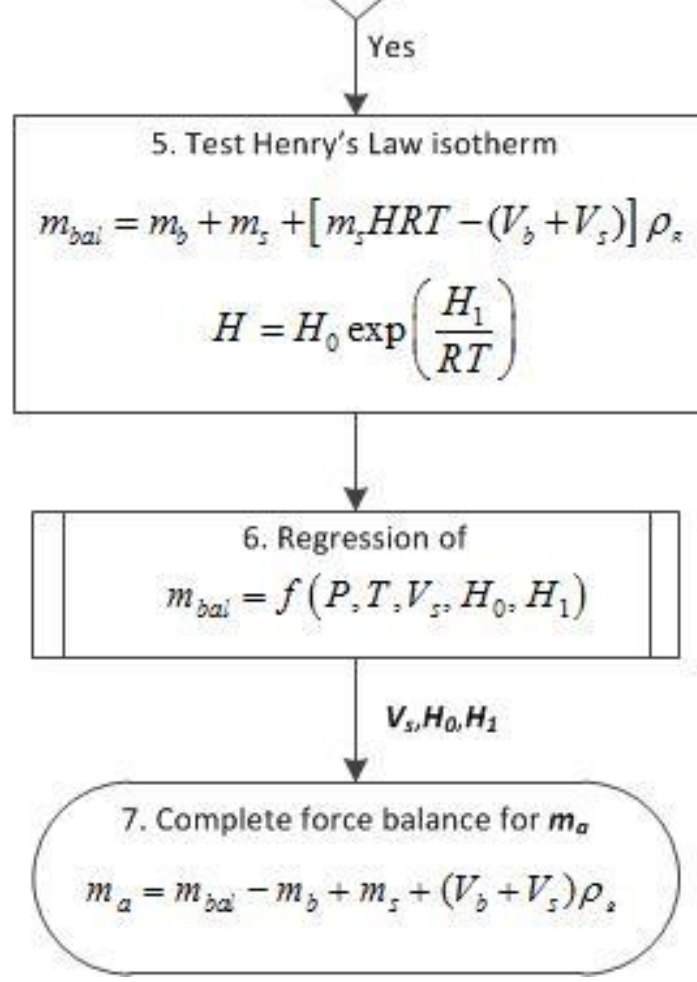

Figure 2 Overview of algorithm used to determine uptake of helium from gravimetric adsorption measurements [1]. 


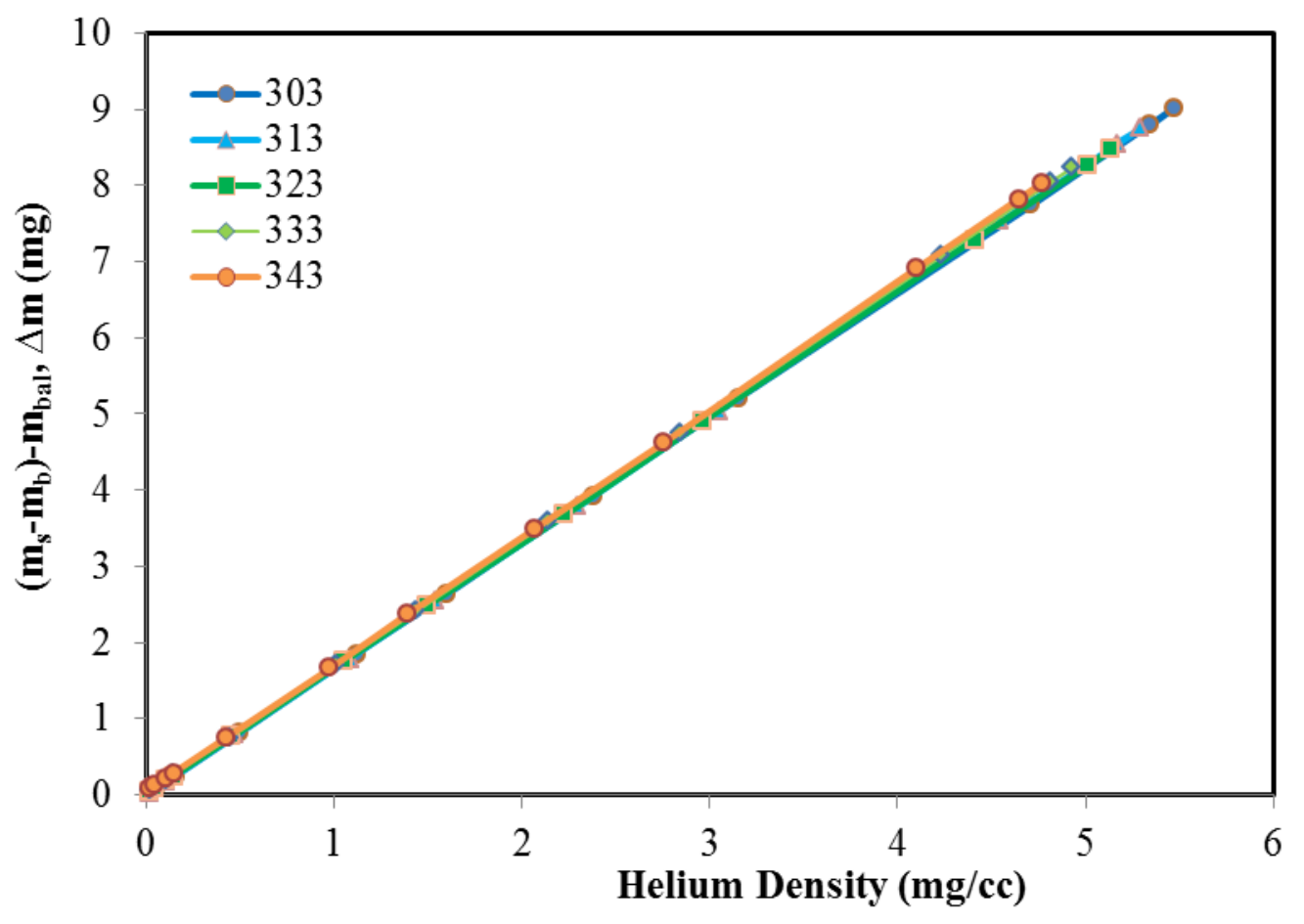

Figure 3 Mass change $\Delta m$ measured from force balance on clinoptilolite-rich Escott zeolite plotted against the bulk helium fluid density at temperatures from $303 \mathrm{~K}$ to $343 \mathrm{~K}$. 


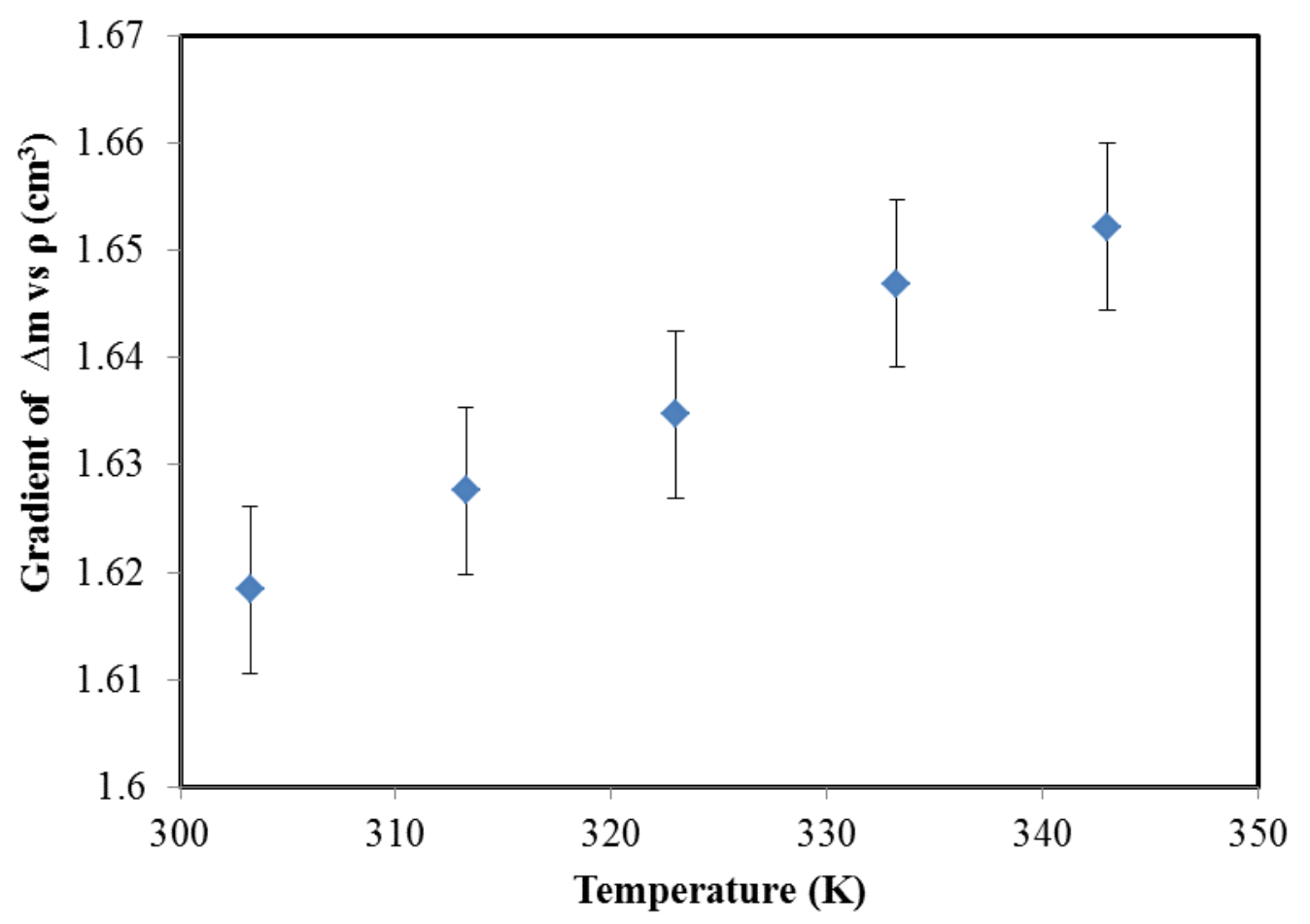

Figure 4 Volume $V_{b}+V_{s}$ determined at each measured adsorption temperature from the slopes of the $\Delta \mathrm{m}$ against fluid density $\rho_{\mathrm{g}}$ plots shown in Figure 3 for Escott zeolite. 


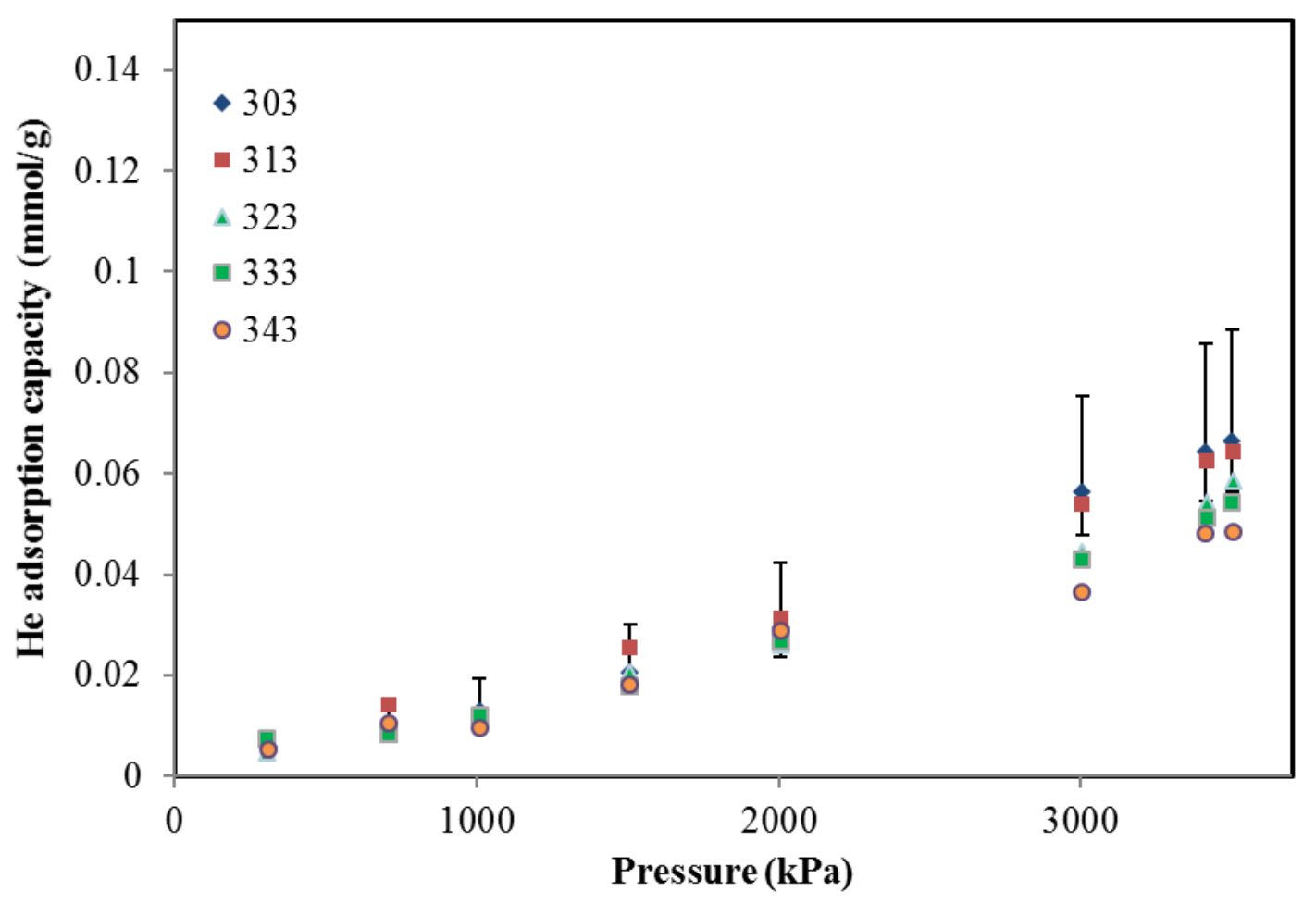

Figure 5 Helium surface excess adsorption capacity on Escott zeolite measured by the gravimetric method at temperatures from $303 \mathrm{~K}$ to $343 \mathrm{~K}$. The error bars marked on the $303 \mathrm{~K}$ isotherm represent the uncertainty in the helium adsorption capacity estimated from (1) the measurement uncertainty in the magnetic suspension balance and (2) the uncertainties that result from the data analysis procedures used to determine $v_{s, G T}$, which includes the uncertainty due to the heat of adsorption. 


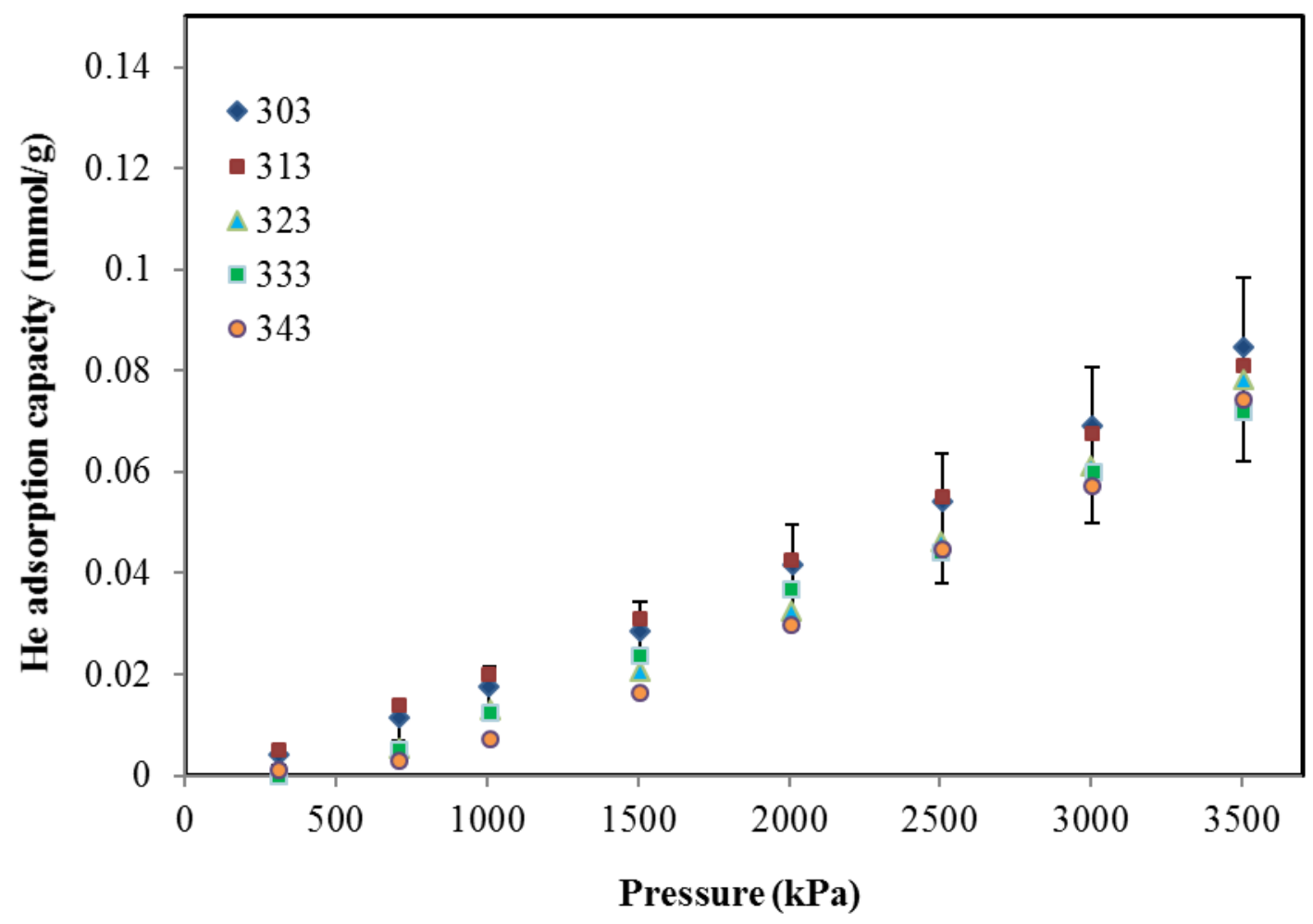

Figure 6 Helium surface excess adsorption capacity on zeolite 3A measured by the gravimetric method at temperatures from $303 \mathrm{~K}$ to $343 \mathrm{~K}$. The error bars marked on the $303 \mathrm{~K}$ isotherm represent the uncertainty in the helium adsorption capacity estimated from (1) the measurement uncertainty in the magnetic suspension balance and (2) the uncertainties that result from the data analysis procedures used to determine $v_{s, G T}$, which includes the uncertainty due to the heat of adsorption. 


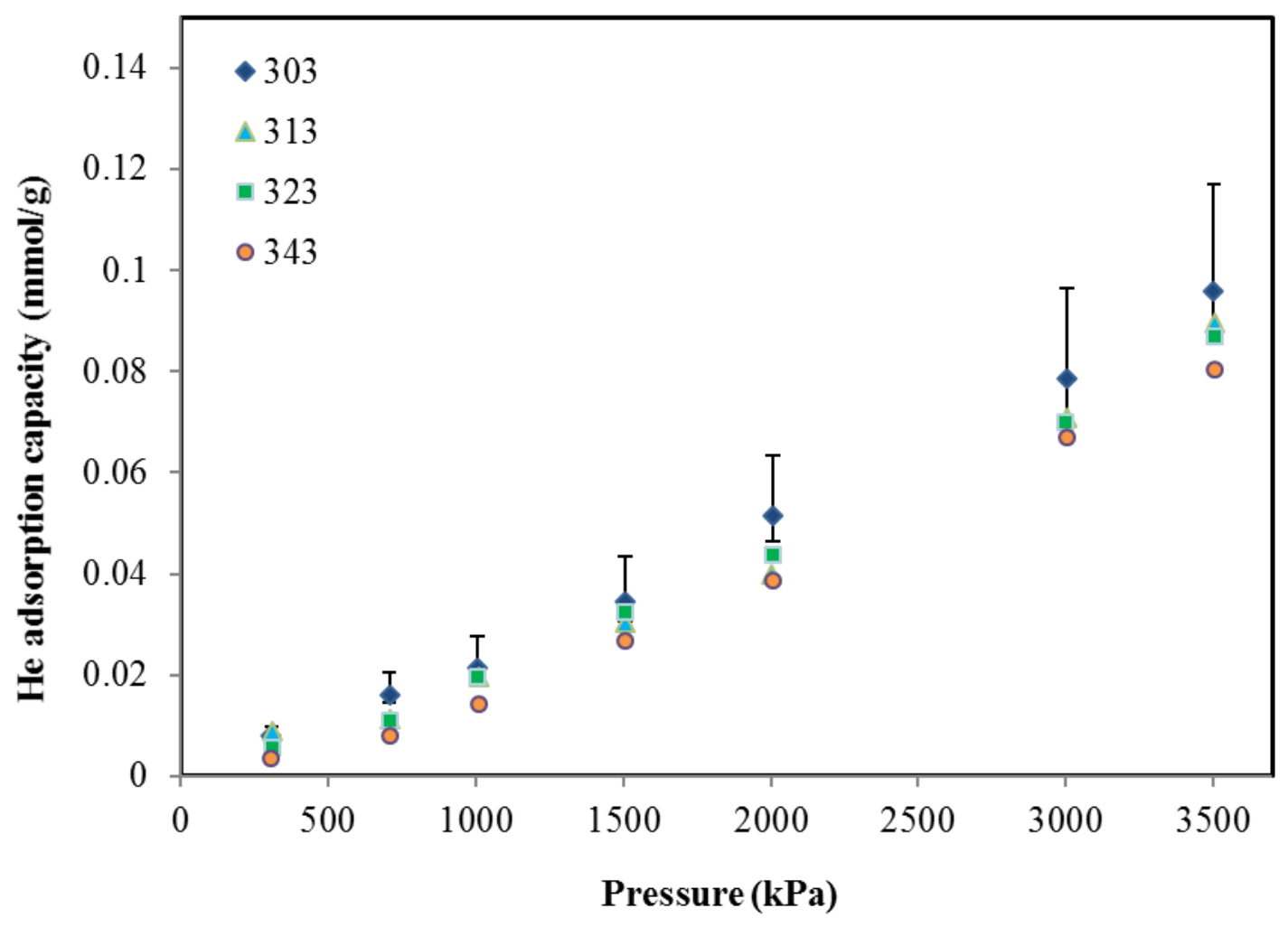

Figure $7 \quad$ Helium surface excess adsorption capacity on zeolite 4A measured by the gravimetric method at temperatures from $303 \mathrm{~K}$ to $343 \mathrm{~K}$. The error bars marked on the $303 \mathrm{~K}$ isotherm represent the uncertainty in the helium adsorption capacity estimated from (1) the measurement uncertainty in the magnetic suspension balance and (2) the uncertainties that result from the data analysis procedures used to determine $v_{s, G T}$, which includes the uncertainty due to the heat of adsorption.. 


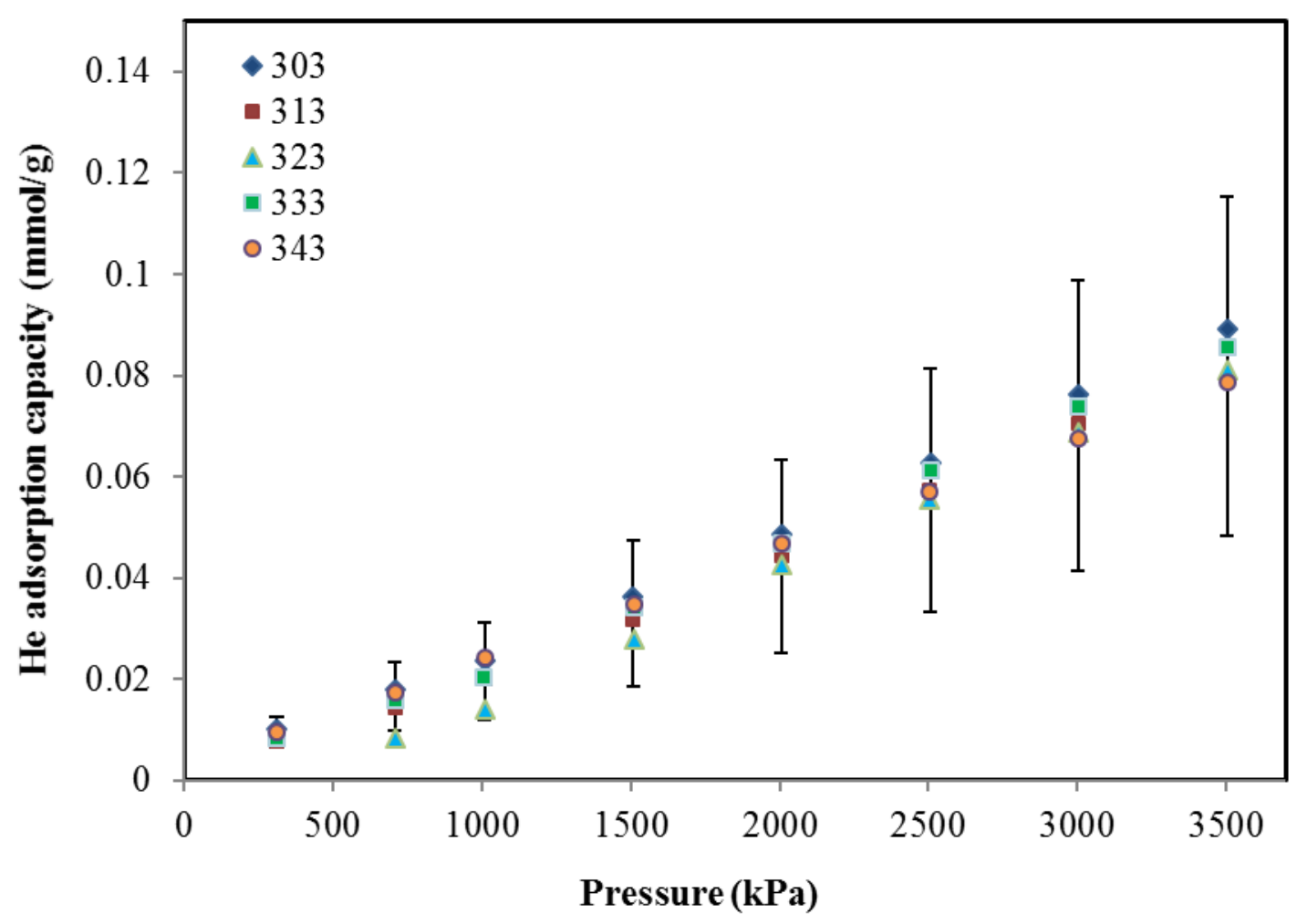

Figure 8 Helium surface excess adsorption capacity on carbon molecular sieve CMS 3K-172 measured by the gravimetric method at temperatures from $303 \mathrm{~K}$ to $343 \mathrm{~K}$. The error bars marked on the $303 \mathrm{~K}$ isotherm represent the uncertainty in the helium adsorption capacity estimated from (1) the measurement uncertainty in the magnetic suspension balance and (2) the uncertainties that result from the data analysis procedures used to determine $v_{s, G T}$, which includes the uncertainty due to the heat of adsorption.. 

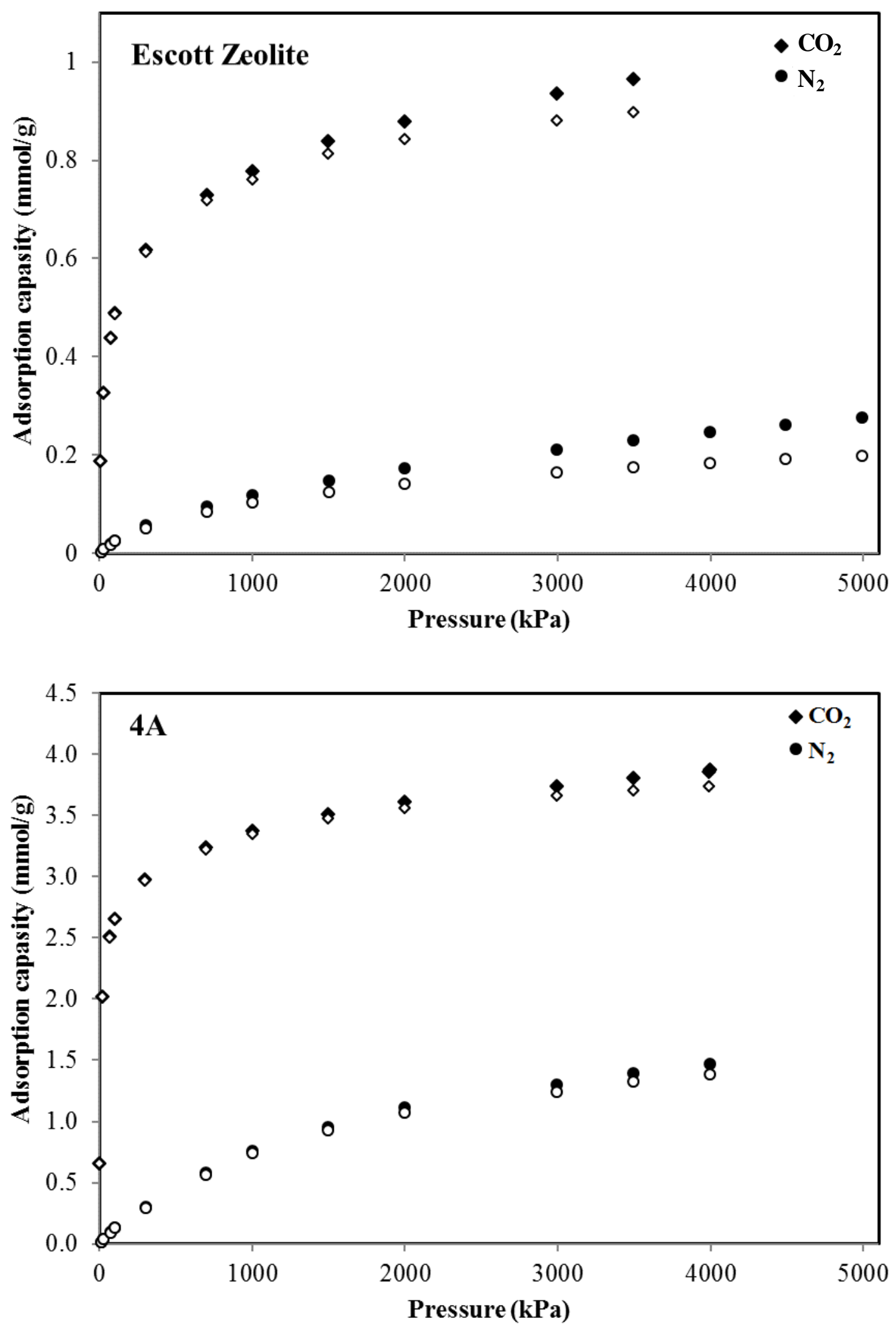


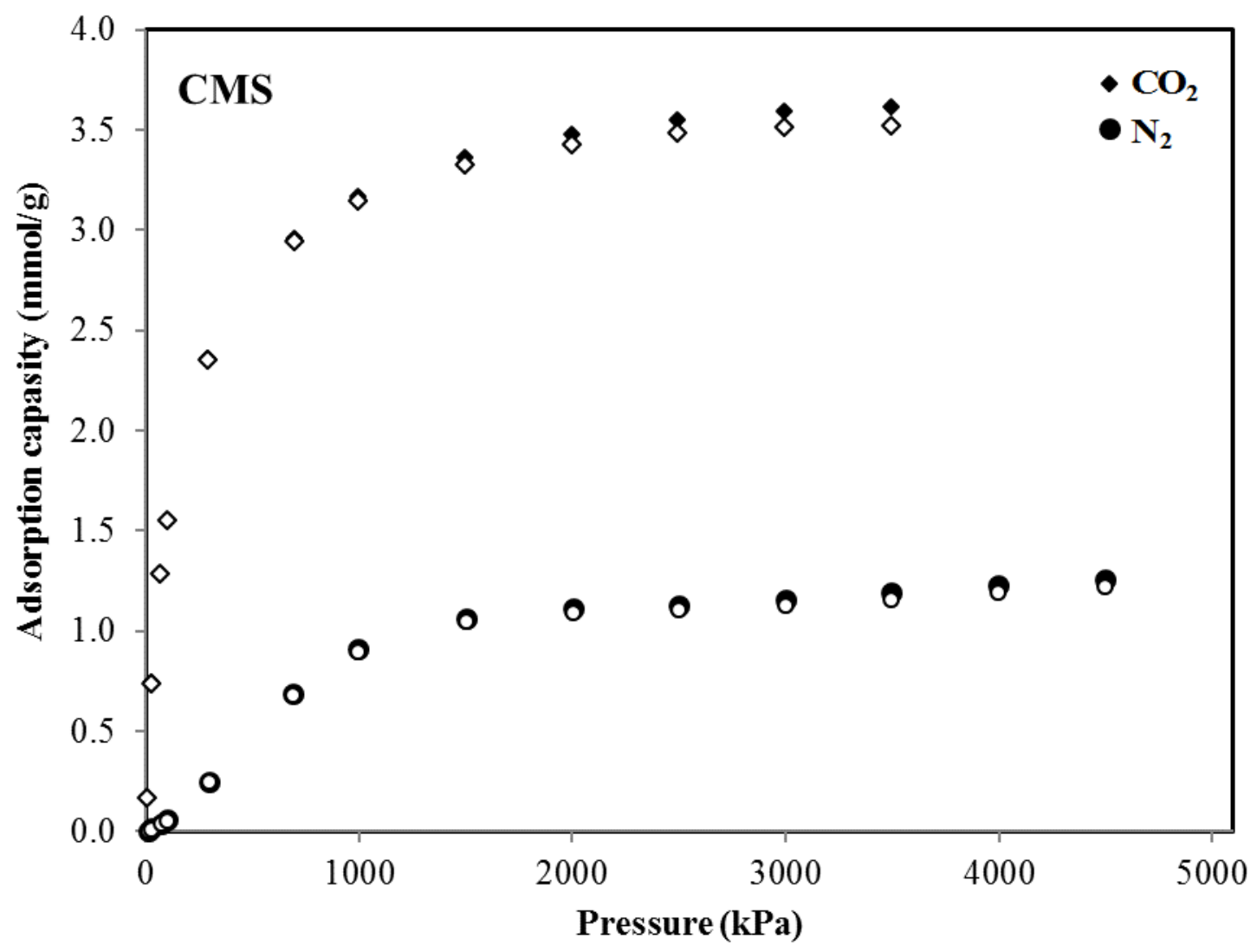

Figure 9 Change in adsorption capacity of carbon dioxide $(\bullet)$ and nitrogen $(\bullet)$ adsorption (mmol/g) on Escott zeolite (at $303 \mathrm{~K}$ ), zeolite 4A (at $298 \mathrm{~K}$ ) and CMS (at $313 \mathrm{~K}$ ) by using (i) the specifc impenetrable solid volume $v_{s, G T}$ from Gumma and Talu [1] (filled symbols) and (ii) the specific impenetrable solid volume $v_{s, P y c}$ from standard helium pycnometry (empty symbols). 